\title{
A method to analysis and design for long life power converter
}

\author{
Pang H. M. \\ Department of Electrical and Electronic Engineering \\ The University of Hong Kong \\ Hong Kong SAR, China
}

\author{
Pong M. H. Bryan, Senior Member IEEE \\ Department of Electrical and Electronic Engineering \\ The University of Hong Kong \\ Hong Kong SAR, China
}

\begin{abstract}
Engineers are always looking for more reliable or longer life power converters. Electrolytic capacitor is the critical component to be considered. Using the powerful calculation tools like Mathcad and Matlab and allowable life model, this paper aims at proposing a method to optimize the circuit design to lower the current ripple through the electrolytic capacitor in order to reach for longer capacitor life. Comparison between two modes of operation and the two converter topologies, Forward and Flyback, are made as well. This work provides a guideline to design power converters for long life application like LED driver.
\end{abstract}

\section{INTRODUCTION}

There is an increasing demand for long life power converters. Medical equipment, telecommunication system and LED lighting drivers need long life power converters at least with the life time of the load. Electrolytic capacitors are critical elements in Power Electronics circuits. They serve purposes like energy storage or filtering of rectified AC voltage ripple [1-4, 7]. An electrolytic capacitor is also one of the most expensive components in a power electronics circuit. Moreover, these capacitors must endure relatively high ripple current which lead to self heating. Most likely, the electrolytic capacitor is prone to have shorter life than other electronic devices in the circuit except mechanical fans [1-9]. For these reasons special attention is paid to factors affecting life of this component.

Several factors can cause failure of the electrolytic capacitor, such as extremely cold temperature, heat, high voltages, transients, extreme frequencies or reverse bias. The most influential factor is heating up of the electrolyte, which determines how fast the non-solid electrolytic solution is evaporated, causing the degradation in the electrical parameters. The dissipation heat generated by ripple current is one of the most important components [1, 5-6, 9]. The dissipation heat generated by the ripple current is an important component affecting the core temperature. Therefore, apart from ambient temperature, attention will also be given to factors like thermal resistance from core to ambient and the power loss by ripple current on the ESR.
Currently, few papers have worked on optimizing the electrolytic capacitor life from circuit design aspect. There is common view that capacitor life can be increased by operating below maximum ratings $[1-5,7,9]$. A. Riz et al. stated the useful life can be prolonged by lower operating voltage, current or ambient temperature and by cooling measures [4]. M. L. Gasperi showed the impact of ripple current on capacitor life, with experimental proof [5]. M. Huber et al. proposed ripple current reduction method of DC Link electrolytic capacitor by switching pattern optimization to prolong its life [9]. But there is yet optimization of switching power supply electrolytic capacitor, which this paper aims at prolonging the capacitor life through optimized circuit design.

\section{MODELING}

Analyzing and understanding the impact of each circuit parameter to electrolytic capacitor life is crucial and is achieved by an appropriate model. Electrolytic capacitor life model is the starting point, followed by converter model from which the switch current shape is calculated out. The section is completed by calculation of capacitor ripple current.

\section{A. Electrolytic capacitor life model}

Several life models for electrolytic capacitor have been published. Two common ones are ESR determination from capacitor inner pressure and life prediction from estimated core temperature [1-8]. However, only the latter one is a predictive approach that allows circuit optimization in design stage is proposed by M. L. Gasperi $[5,11]$. The Arrhenius' theory is a common tool in capacitor industry for life prediction purpose.

$$
\frac{L_{p}}{L_{r}} \approx 2^{\frac{{ }_{r}-T_{p}}{10}}
$$

where Lp: predicted life; Lr: rated operating life; Tr: rated core temperature; Tp: actual core temperature. 
The core temperatures $\mathrm{Tp}$ in (1) is the sum of the selfgenerated heat gradient and ambient temperature in Kevin scale, as shown by (2).

$$
T_{\text {core }}=T_{A}+\alpha \Delta T
$$

where Tcore: core temperature; TA: surface temperature; $\Delta \mathrm{T}$ : surface heat rise; $\alpha$ : temperature factor.

Temperature rise is a function of the electrical resistance and the thermal resistance is calculated from (3) to (5). Thermal resistance is difficult to estimate but obtainable from manufacturers. It also depends on the internal dimensions [1, $3,5-6,11]$.

$$
\begin{gathered}
\Delta T=\frac{I^{2} \times E S R}{\beta \times S} \\
\beta=2.3 \times 10^{-3} \times S^{-0.2} \\
S=2 \pi\left(r^{2}+r h\right)
\end{gathered}
$$

where I: ripple current (Arms); ESR: equivalent series resistance of capacitor; $\quad \beta$ : thermal resistance $\left(\mathrm{W} /{ }^{\circ} \mathrm{C} \cdot \mathrm{cm}^{2}\right)$; $\mathrm{S}$ : surface area of capacitor $\left(\mathrm{cm}^{2}\right)$; h: capacitor height $(\mathrm{cm})$; r: capacitor radius $(\mathrm{cm})$.

ESR increases over long time operation but decreases with temperature and frequency rises [1-3, 5-6]. As the ESR increases, heat generated raises the temperature and deteriorates the capacitor. This factor has already been accounted for in the life parameters provided by manufacturers of quality capacitors [10]. Thermal and frequency dependence of the ESR are modeled by (6).

$$
R=R_{o x}(f)+R_{s p}(T)
$$

ESR at specific condition (generally $20^{\circ} \mathrm{C}, 120 \mathrm{~Hz}$ ) can be calculated from the dissipation factor $(D F)$ as $(7)$, as worst case $[3,14]$.

$$
R_{120}=\frac{D F}{2 \pi f C}
$$

Manufacturer provides the frequency multiples for current ripple (Kf). The ESR at different frequencies can be calculated from these multiples $[6,10,14]$.

$$
R_{100 K}=\frac{R_{120}}{K f_{100 K}^{2}}
$$

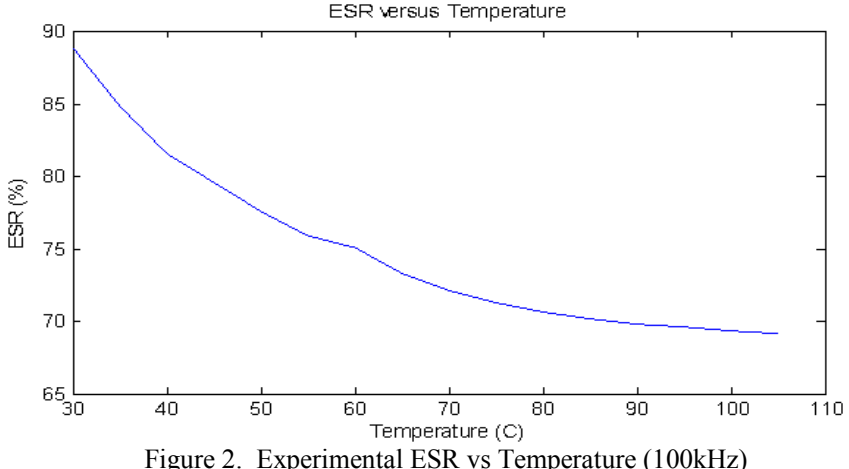

Temperature dependence of ESR is modeled by $(9)[3,5]$.

$$
R(T)=R_{\text {base }} e^{\frac{T_{\text {base }}-T_{\text {core }}}{E}}
$$

where Rbase: $\mathrm{R}$ at base temperature; Tbase: base measurement temperature; E: temperature sensitivity factor.

The sensitivity factor (E) here is not easy to obtain. ESR against temperature plot shows that ESR begins to level off above $70^{\circ} \mathrm{C}$. Taking average over this reasonable temperature range, the ESR can be estimated. Another approach is to find the approximate equation by curve fitting used in later section.

\section{B. Switch current waveform model (Flyback and Forward)}

Predicting the capacitor current waveform is one of the major steps to achieve optimization as the capacitor current greatly affect the amount of self-heat generated. Once the converter parameters are designed and input and output voltages are specified, the capacitor currents should be found. Switching current waveform is a reachable parameter in power converters. Deriving capacitor current waveform from the switching waveform is no more than processing simple calculations. A simple Flyback and Forward converter switch model can tell the switching current waveform in full load conditions.

Equations (9) and (10) are the steady state equation for CCM Flyback at switch on and switch off period respectively. Solving (9) and (10), the waveform parameters can be obtained.

a) CCM Flyback switch on period:

$$
L \times f s \times \frac{I d}{D}=V i n-\frac{\text { Iout }}{n \times(1-D)} \times R p r i
$$

CCM Flyback switch off period:

$$
L \times f S \times \frac{I d}{1-D}=V o u t+V f+\frac{\text { Iout }}{n \times(1-D)} \times R \mathrm{sec}
$$

where Id: the switch delta current; D: switch duty; fs: switch frequency; L: transformer inductance; $\mathrm{n}$ : transformer turn ratio; Vf: output diode voltage drop. 


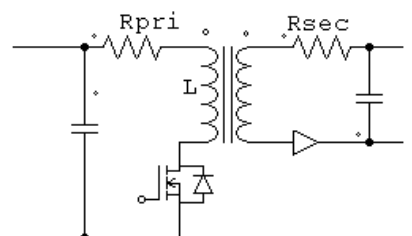

Flyback

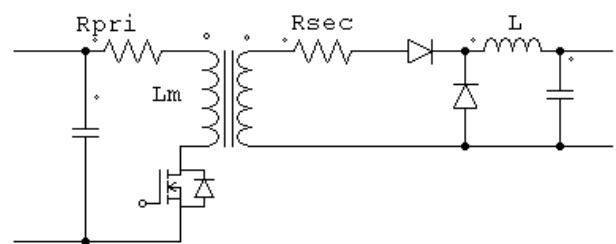

Forward

Figure 3. Generic circuit diagram for Flyback and Forward

Similarly, DCM Flyback steady state current can be worked out by (11) to (13). Equations (14) to (19) are those for a Forward converter. Fig.4 shows typical switch current waveforms and the parameters to be calculated.

b) DCM Flyback:

$$
\begin{gathered}
L \times f_{s} \times \frac{2 I p}{D}=\text { Vin }-I p \times R p r i \\
L \times f_{S} \times \frac{2 I p}{n \times D^{\prime}}=\text { Vout }+V f+n \times I p \times R \text { sec }
\end{gathered}
$$

$$
n \times I p \times D^{\prime}=\text { Iout }
$$

c) CCM Forward:

$$
\begin{gathered}
L \times f s \times n \times \frac{\text { Id }}{D}=\frac{\text { Vin }}{n}-\text { Vout }-V f-\frac{\text { Iout }}{n} \times \text { Rpri }- \text { Iout } \times R \sec \\
L^{*} f^{*} n^{*} \frac{I d}{1-D}=\text { Vout }+ \text { Vf }+ \text { Iout }^{*} R \mathrm{sec} \\
i_{m}=\frac{\text { in } \times D}{L_{m} \times f S}
\end{gathered}
$$

where L: output filter inductance; Lm: transformer magnetizing inductance; im: magnetizing current.

d) DCM Forward:

$$
\begin{gathered}
L \times f s \times \frac{2 n \times I p}{D}=\frac{\text { Vin }}{n}-\text { Vout }-n \times R \sec \times I p-R p r i \times I p \\
L \times f s \times \frac{2 I p}{n \times D^{\prime}}=\text { Vout }+R \sec \times I p
\end{gathered}
$$

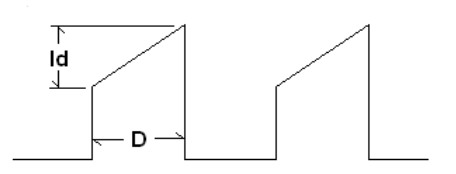

(a)

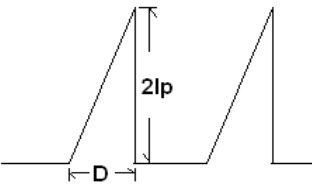

(b)

$$
D=-D^{\prime}+\frac{\text { Iout }}{n \times I p}
$$

$$
i_{m}=\frac{\operatorname{Vin} \times D}{L_{m} \times f S}
$$

\section{Calculating capacitors ripple current}

Switch current parameters, including lower peak (iL), higher peak (iH), switch duty (D) and switch off duty (D') in DCM, are the variables obtained from the converter models. With these known variables one can figure out the waveform shape [14]. Simple derivation can then help us to reach for input and output capacitor currents. Assumption made here is the current input and current output of the converter is constant, which can be easily justified. Input side of the converter always equips with common mode and differential mode filters than smoothen the input current. And the output constant load is a usual practice in steady state. Figures below show the switch current shape and how is it related to the input capacitor current waveform in CCM and DCM separately. Mathematical equations to work out the capacitors' current are shown as well. The ripple current $\mathrm{RMS}^{2}$ can be calculated accordingly. Fig. 5 shows the relationship between the switch current and capacitors' current shape for Buck and Buck-boost type, the bases of Forward and Flyback converters. It can be easily seen that the RMS values of the input and output capacitors can be expressed in terms of the duty cycle $\mathrm{D}$ and current peaks. These values highly depend on the power converter design parameters and they can be designed to reduce the capacitor RMS values for long operation life.

a) CCM Flyback converter: Input capacitor current RMS'

$$
\begin{aligned}
I_{d r m s}{ }^{2}= & \frac{1}{12}\left[\left(i_{L}{ }^{2}+i_{H}{ }^{2}\right)\left(-3 D^{2}+4 D\right)\right. \\
& \left.+i_{L} i_{H}\left(-6 D^{2}+4 D\right)\right]
\end{aligned}
$$

Output capacitor current $\mathrm{RMS}^{2}$ :

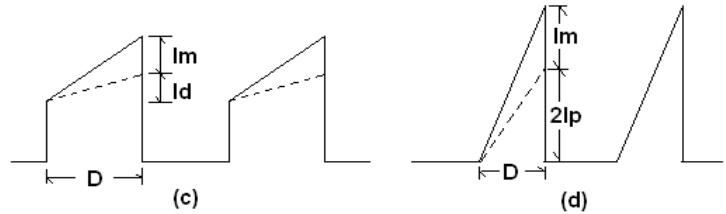

(d)

Figure 4. Switch current for a)CCM Flyback b)DCM Flyback c)CCM Forward d)DCM Forward 


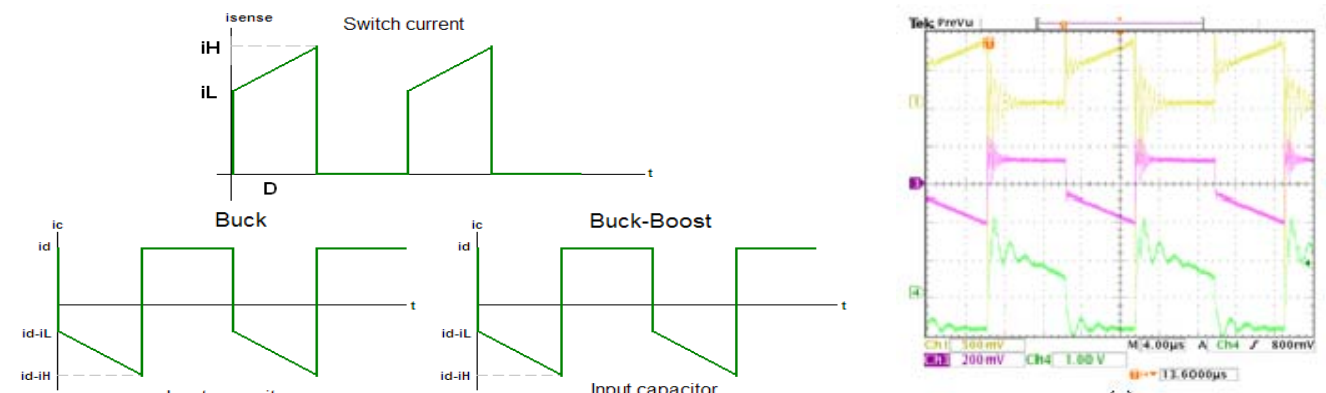

Input capacitor
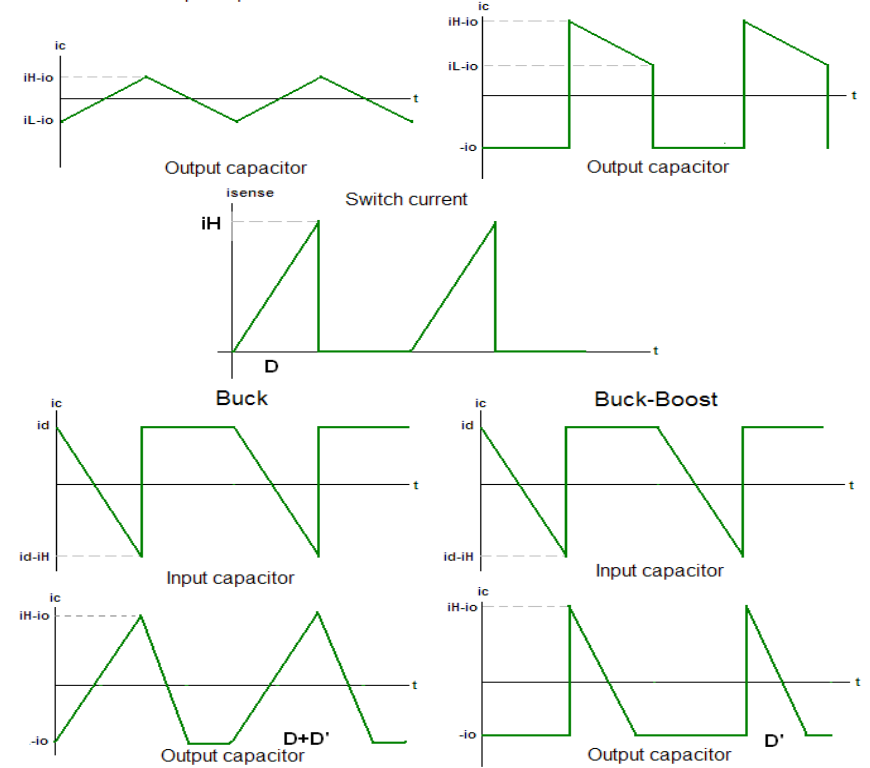

Figure 5. Switch current and capacitors current for CCM and DCM cases

$$
\begin{aligned}
I_{\text {orms }}{ }^{2}= & \frac{1}{12}\left[\left(i_{L \mathrm{sec}}{ }^{2}+i_{H \mathrm{sec}}{ }^{2}\right)\left(-3 D^{2}+2 D+1\right)\right. \\
& \left.+i_{L \mathrm{sec}} i_{H \mathrm{sec}}\left(-6 D^{2}+8 D-2\right)\right]
\end{aligned}
$$

where $\mathrm{iLsec}=\mathrm{n} * \mathrm{iL} ; \mathrm{iHsec}=\mathrm{n} * \mathrm{iH}$.

b) CCM Forward converter:

$$
\begin{aligned}
& I_{d r m s}{ }^{2}=\frac{1}{12}\left[\left(i_{L}{ }^{2}+i_{H}{ }^{2}\right)\left(-3 D^{2}+4 D\right)\right. \\
& \left.+i_{L} i_{H}\left(-6 D^{2}+4 D\right)+i_{m}{ }^{2} D_{r}\right] \\
& I_{o r m s}^{2}=\frac{1}{12}\left(n\left(i_{H}-i_{m}\right)-n i_{L}\right)^{2}
\end{aligned}
$$

where Dr: reset duty.

It is assumed that the magnetizing current is much smaller than that of switch load current that equation (22) is accurate. c) DCM Flyback converter:

$$
I_{d r m s}{ }^{2}=\frac{1}{12} i_{H}^{2}\left(-3 D^{2}+4 D\right)
$$

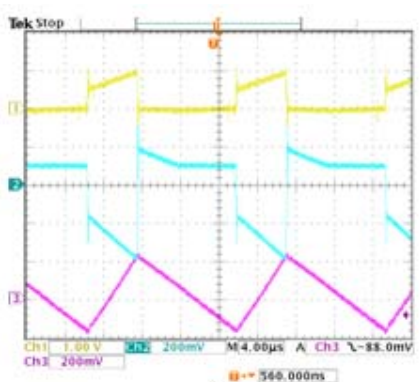

(b)

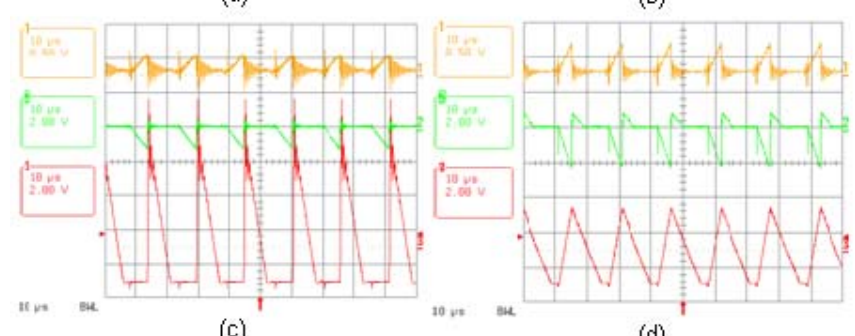

(c)

(d)

Figure 6. Experimental waveforms for a)CCM Flyback, b)CCM Forward, c)DCM Flyback, d)DCM Forward upper: switch current; middle: input capacitor current; lower: output capacitor current

$$
I_{\text {orms }}^{2}=\frac{1}{12} i_{H \mathrm{sec}}^{2}\left(-3 D^{\prime 2}+4 D^{\prime}\right)
$$

d) DCM Forward converter:

$$
\begin{gathered}
I_{d r m s}{ }^{2}=\frac{1}{12} i_{H}{ }^{2}\left(-3 D^{2}+4 D\right) \\
I_{o r m s}{ }^{2}=\frac{1}{12} n\left(i_{H}-i_{m}\right)^{2}\left[-3\left(D+D^{\prime}\right)^{2}+4\left(D+D^{\prime}\right)\right]
\end{gathered}
$$

Fig. 6 shows the experiment captured waveforms which are comparable to the expected ones.

\section{ANALYSIS OF CAPACITOR LIFE IN FLYBACK AND FORWARD CONVERTER}

Putting (1) to (27) into program, the 3-D life plots as follow can be obtained. The variation of working conditions to life change of the converter can then be studied in a mathematical manner. Working temperature is the trivial factor to life and is assumed constant since it has not interest to circuit design. Line voltage and load current variations to a fixed design are the interesting factors to study. Comparison between Flyback and Forward converters lives is made. Afterward, circuit parameters variation to a fixed specification (defined input and output) is also studied in next section. All these issues can help to choose the more reliable configuration for suitable applications. Testing capacitors are as follow:

TABLE I. TESTING CAPACITORS FOR COMPARISON

\begin{tabular}{|c|c|c|}
\hline \multicolumn{3}{|c|}{ Flyack } \\
\hline $\begin{array}{c}\text { Input } \\
\text { capacitor }\end{array}$ & $\begin{array}{c}\text { Rubycon MXG } \\
\text { series 450V } 180 \mathrm{uF}\end{array}$ & Measured ESR $\left(50^{\circ} \mathrm{C} 100 \mathrm{kHz}\right):$ \\
\hline
\end{tabular}




\begin{tabular}{|c|c|c|}
\hline & & $104 \mathrm{~m} \Omega$ \\
\hline $\begin{array}{c}\text { Output } \\
\text { capacitor }\end{array}$ & $\begin{array}{c}\text { Rubycon ZL series } \\
35 \mathrm{~V} 1800 \mathrm{uF}\end{array}$ & $\begin{array}{c}\text { Measured } \mathrm{ESR}\left(50^{\circ} \mathrm{C} 100 \mathrm{kHz}\right): \\
16 \mathrm{~m} \Omega\end{array}$ \\
\hline \multicolumn{3}{|c|}{ Forward } \\
\hline $\begin{array}{c}\text { Input } \\
\text { capacitor }\end{array}$ & $\begin{array}{c}\text { Rubycon MXG } \\
\text { series } 450 \mathrm{~V} 180 \mathrm{uF}\end{array}$ & $\begin{array}{c}\text { Measured } \mathrm{ESR}\left(50^{\circ} \mathrm{C} 100 \mathrm{kHz}\right): \\
104 \mathrm{~m} \Omega\end{array}$ \\
\hline $\begin{array}{c}\text { Output } \\
\text { capacitor }\end{array}$ & $\begin{array}{c}\text { Rubycon } \mathrm{ZL} \mathrm{series} \\
35 \mathrm{~V} 680 \mathrm{uF}\end{array}$ & Measured $\mathrm{ESR}\left(50^{\circ} \mathrm{C} 100 \mathrm{kHz}\right):$ \\
\hline \multicolumn{2}{|c|}{}
\end{tabular}

Capacitance is selected according to the voltage ripple

Fig. 7 shows the line voltage and load variations to input and output capacitors' lives in general-designed CCM (left) and DCM (right) Flyback converters at an ambient temperature of $50^{\circ} \mathrm{C}$, which is the appropriate temperature in a closed system. The converter is designed for $90 \mathrm{~V}$ to $240 \mathrm{~V}$ input and $12 \mathrm{~V} 10 \mathrm{~A}$ output. Several interesting points are noticed from these plots:

1) Input capacitor generally handles less current stress than output capacitor in the Flyback converter for both CCM and DCM. In other words, output capacitor tends to dominate the life of a Flyback converter. Note that this is not a straight rule and highly depend on the transformer design and the electrolytic capacitors selected. It can vary but is always true for general design.

2) The CCM Flyback design tends to last longer than the DCM one under the same loading conditions. For this example is around 100 times better.

3) Line voltage and load variations do not have much impact on input capacitor life in CCM and DCM Flyback;

4) In CCM Flyback, increased load current and reduced line voltage shorten the output capacitor life.

5) In DCM Flyback, output capacitor life is not affected by line voltage but reduced by increasing the load.

Transformer design: $\mathrm{L}=500 \mathrm{uH}, \mathrm{n}=60 / 8, \mathrm{fs}=65 \mathrm{kHz}(\mathrm{CCM})$; $\mathrm{L}=100 \mathrm{uH}, \mathrm{n}=22 / 3$, fs $=65 \mathrm{kHz}(\mathrm{DCM})$.

The figures are alarming but explainable. The major factor is under full load condition Flyback secondary side current ripple is much higher than expected and far beyond the rated current ripple provided by the capacitor manufacturers. The enlarged capacitor self-generated heat greatly accelerates the electrolyte evaporation and sharply reduces its life. This also explains why there is essential to parallel many output
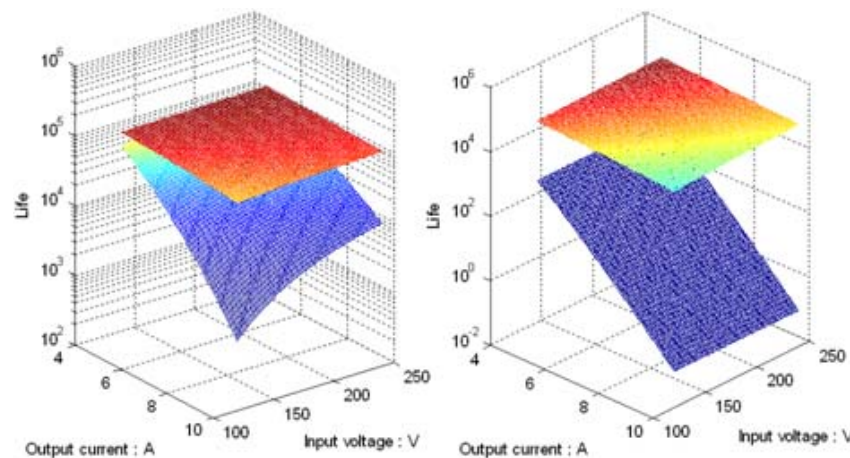

Figure 7. Life versus input and load variation for CCM (left) and DCM (right) Flyback

upper: input capacitor; lower: output capacitor capacitors with higher-than-required capacitance to share the current ripple in industrial products.

Same analysis is applied to the Forward converters. The converter is designed for $90 \mathrm{~V}$ to $240 \mathrm{~V}$ input and $12 \mathrm{~V} 10 \mathrm{~A}$ output, same as pervious Flyback. Working temperature is 50 ${ }^{\circ} \mathrm{C}$. Points to be noted are:

1) In CCM mode, output capacitor generally handles less current stress than input capacitor in the Forward converter. Input capacitor tends to dominate the life of a CCM Forward converter.

2) In DCM mode, however, output capacitor dominates the life of Forward converter.

3) The CCM Forward design lasts much longer than the DCM one especially under full load condition. Under full load condition it can be as much as a thousand times better (depending on the transformer design and the electrolytic capacitors selected).

4) Line voltage and load variations do not have much impact on both capacitors lives in CCM Forward.

5) In DCM Forward, increased load current and line voltage sharply shorten the output capacitor life.

Magnetic design: Lchoke $=33 \mathrm{uH}, \mathrm{n}=20 / 6$, fs $=65 \mathrm{kHz}(\mathrm{CCM})$; Lchoke $=4 \mathrm{uH}, \mathrm{n}=20 / 4$, fs $=65 \mathrm{kHz}(\mathrm{DCM})$.

The sharp reduction of capacitor life when forward operates in DCM can be explained by the sharply increased current ripple. In CCM, only small AC portion charges into and out of the capacitor as the filter choke is large enough and the DC bias level does no heating effect on the capacitor. In DCM the filter choke is however too small to maintain the DC level. Both Forward and Flyback converter has reduced life in DCM mode. Therefore, it is recommended to use CCM operation for life sensitive designs.

Comparison between Flyback and Forward converters lives is valuable. Flyback converter is always considered to be favorable isolated topology for low power output applications for its low cost, simplicity and multi-output availability. One of the familiar applications for Flyback is LED driver. However, in the analysis of the capacitor life between a Flyback and a Forward in CCM mode, it is found that the Forward tends to have longer life than the Flyback converter, especially when the load power is high. This gives out the idea
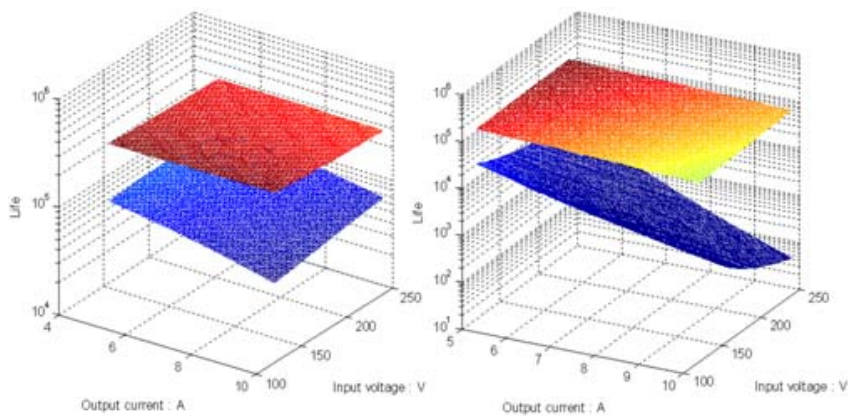

Figure 8. Life versus input and load variation for CCM (left) and DCM (right) Forward

(Left) upper: output capacitor; lower: input capacitor

(Right) upper: input capacitor; lower: output capacitor 


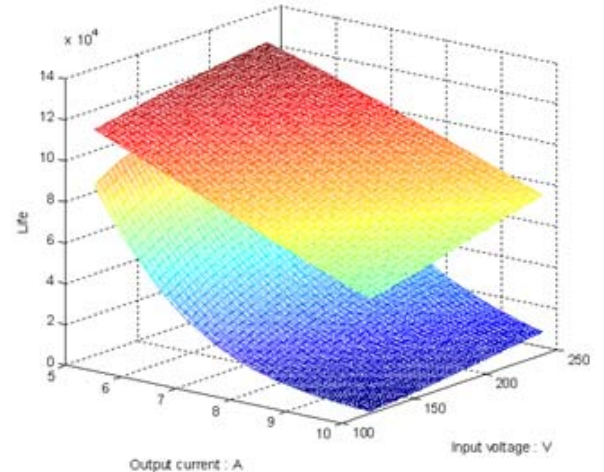

Figure 9. Life versus input and load variation for CCM Forward (upper) and Flyback (lower)

why buck type topology (Forward) is more suitable for LED drivers. Forward is also more favorable for higher power applications $(>100 \mathrm{~W})$ considering their reliability.

\section{OPTIMIZING THE CONVERTER DESIGN FOR LONGER LIFE}

From previous deviations and analysis, it is well accepted that capacitor current ripple does have huge impact on capacitor life through self-heating. If the converter circuit is designed such that the current ripple stress on the electrolytic capacitors are reduced, it is possible to optimize the converter with longer working life. But what are the parameters affecting the current ripple value, which are controllable? Looking into the previous simplified circuit models, it can be easily told that those are inductance L, transformer turn ratio $n$ and switch frequency fs. These parameters determine the peak magnitude and current shape, which in turn determine the RMS current value of the capacitors. Other parameters are either incontrollable or little impact on capacitor currents. The plots below can vary when circuit parameters, capacitor types or loading conditions change, but the trend and the design approach are the same. The test condition in this section for both converter topologies are operating in CCM to output $12 \mathrm{~V}$ $5 \mathrm{~A}$ with input voltage $120 \mathrm{~V}$.

Fig. 10 shows the frequency, inductance and transformer turn ratio variation to capacitor life changes in a Flyback (left) and a Forward (right) converter individually, assuming the other two parameters are constant. Increasing the switching frequency can increase the capacitor life. And the output capacitors of both topologies are more sensitive to the frequency change than their counterpart input capacitors. Therefore the life improvement to frequency increment is more significant to Flyback.

Comparing with frequency, transformer (choke) inductance and turn ratio shows greater impact on capacitor life. Moreover, the switching frequency is highly restricted by the product size, efficiency and the control. More effort would be paid to transform and choke design. Both greatly determine the current shapes. For both Flyback and Forward converters, there is a sharp drop in capacitors' lives in small inductance values. The converters run deeply into DCM mode in these values causing extremely high current ripple RMS. Cross point between the curves for the input and output capacitor life is the point where both input and output capacitors are under the same current stress. This is not the point with the longest
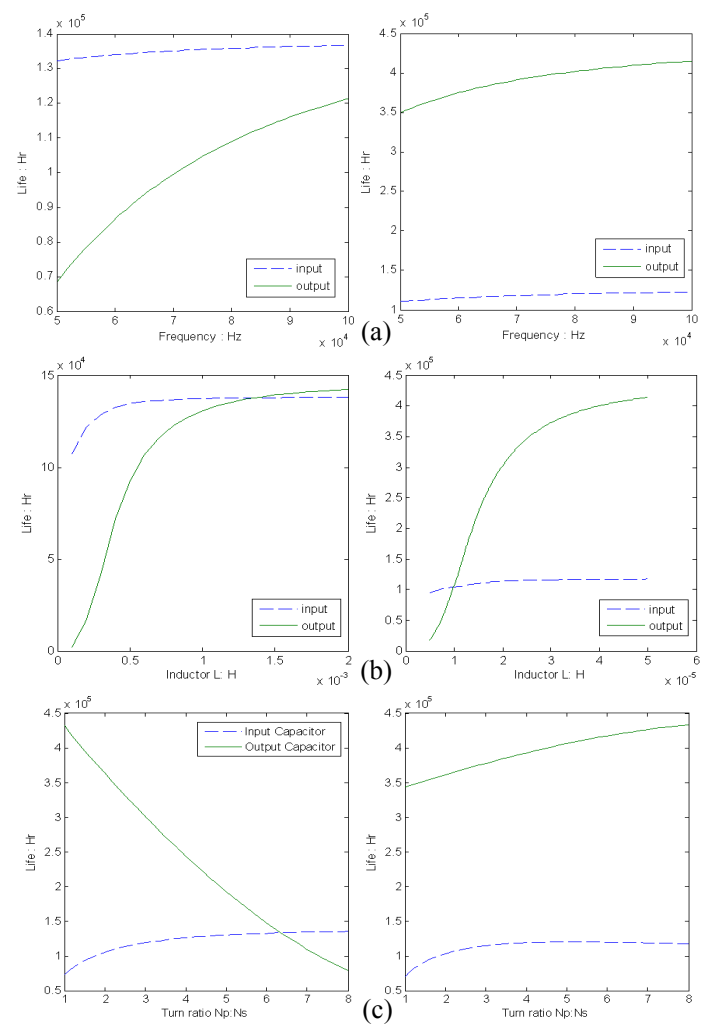

Figure 10. Life versus a)switching frequency, b)inductance c)turn ratio for CCM Flyback (left) and Forward (right)

converter life but above this point the life increment is almost level off. On the other hand, there are restriction to design high inductances, like the losses and core saturation. Therefore, it is recommended to design the inductance just above this point.

Transformer turn ratio affects the current peak magnitude as well as switch duty. Consider the CCM Flyback, increasing turn ratio increases the primary side current ripple while reducing secondary side current ripple. The cross point between two curves is the optimal point where converter life is longest. For the Forward, once it operates in $\mathrm{CCM}$ which high output choke, the current ripple is incomparable to rated ripple of output capacitor. Increasing turn ratio will further increase the life. Note again that figures above are only one of the possible design cases. The situation varies with design specifications but is true for generic design. Optimization in parameter choosing can still be done in a similar way.

Parameter variations affecting capacitor life are presented individually. In design process, however, these parameter values affect each other as well. Consider the switching frequency is determined beforehand by converter size, efficiency or else, the inductance and transformer turn ratio are organized into one three-dimension plot to help obtaining the best values of each, as shown by fig. 11. For Flyback converter, alone the boundary line is the combinations of inductance and turn ratio that give longer converter life than their neighbor points. For Forward converter, the boundary line is where the life starts to drop sharply due to DCM operation. For every inductance there is an optimal turn ratio. The higher the inductance gives the longer converter life but 


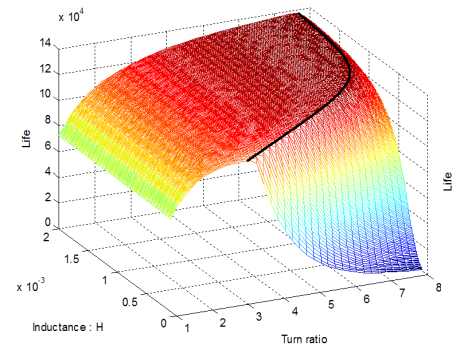

Figure 11. Life versus inductance and turn ratio for CCM Flyback (left) and Forward (right)

the difference is insignificant while adding cost and size. It is recommended to design the inductance just above this boundary.

\section{EXPERIMENTAL RESULTS}

\section{A. Accelerated test on life model}

Though there were numerous papers worked on verification of the life model, an accelerated test was conducted for completeness [5]. The testing media was a DCM flyback converter output capacitor, which was considered to be under high current stress. A current probe measures the capacitor current. The working conditions are listed in the table. The calculated life time is 63 hours. The result is acceptably accurate since manufacturer claims the equation is within $40 \%$ error range. Incomplete temperature control might also accelerate the capacitor death.

TABLE II. ACCELERATED TEST CONDITIONS

\begin{tabular}{|c|c|}
\hline Input voltage & $127 \mathrm{Vdc}$ \\
\hline Output voltage & $12 \mathrm{Vdc}$ \\
\hline Output current & $7 \mathrm{~A}$ \\
\hline Capacitor current RMS & $12.76 \mathrm{Arms}$ \\
\hline Capacitor type & Rubycon $\mathrm{ZL}$ series $35 \mathrm{~V} 1800 \mathrm{uF}$ \\
\hline Measured ESR & $16.8 \mathrm{~m} \Omega\left(65 \mathrm{kHz}, 25^{\circ} \mathrm{C}\right)$ \\
\hline Ambient temperature & $25^{\circ} \mathrm{C}$ \\
\hline
\end{tabular}

\section{B. Design a long life converter for LED lamp}

The verified model was demonstrated to design a $150 \mathrm{~W}$ 2FET-Forward converter for LED street lamp. Input is $400 \mathrm{Vdc}$ and output is $24 \mathrm{~V} 6.25 \mathrm{~A}$. The target converter life is around 50000 operation hours, which is comparable to LED lamp itself. Table shows the selected capacitor. ESR characteristics of the input capacitors obtained by experiment are shown in fig. 13. Curve fitting tool (Matlab) was used to found the mathematical expression and was put into the program to improve the model accuracy.

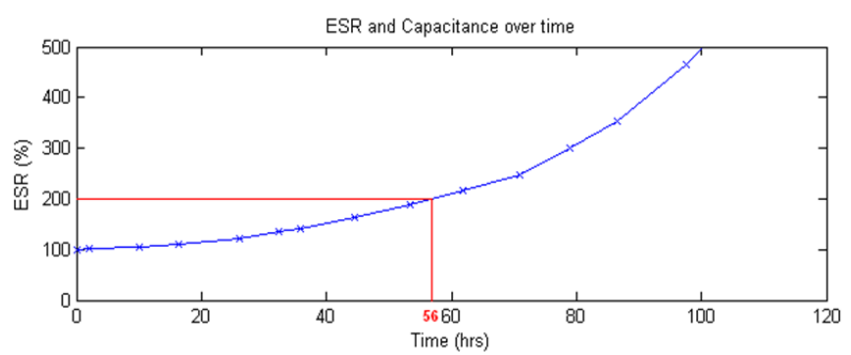

Figure 12. Experiment captured ESR versus time
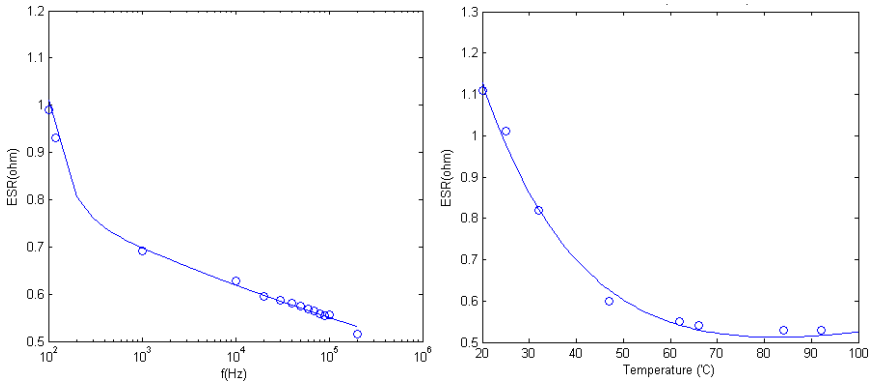

Figure 13. ESR versus frequency (left) and temperature (right)

(AXW 450V 68uF)

TABLE III. CAPACITORS FOR LED LAMP DRIVER

\begin{tabular}{|c|c|}
\hline Input capacitor & Rubycon AXW series 450V 68uF \\
\hline Output capacitor & Rubycon ZL series 35V 1800uF \\
\hline
\end{tabular}

Consider the switching frequency is fixed to be $100 \mathrm{kHz}$, the magnetic component variation is shown by fig. 14. Duty plot was considered to ensure the duty is less than 0.5. Convert the life plot into 2-D plot, the boundary line is where the design is over 50000 working hours. Considering the efficiency and cost, the choke inductance and transformer turn ratio is selected to be $60 \mathrm{uH}$ and 5 respectively. The calculated life is around 66000 hours. The experiment captured waveforms are shown in fig. 15. The input capacitor ripple current is measured to be 0.723 Arms. Substitute this value into the capacitor model, the received life is 63000hours. The discrepancy is due to circuit impedance.

\section{CONCLUSION}

The operating life time of a power converter is often determined by the life of the electrolytic capacitor. The rms value of the capacitor currents should be reduced in order to maximize their life time. Here in this paper a new power converter design method is presented which aims to maximize

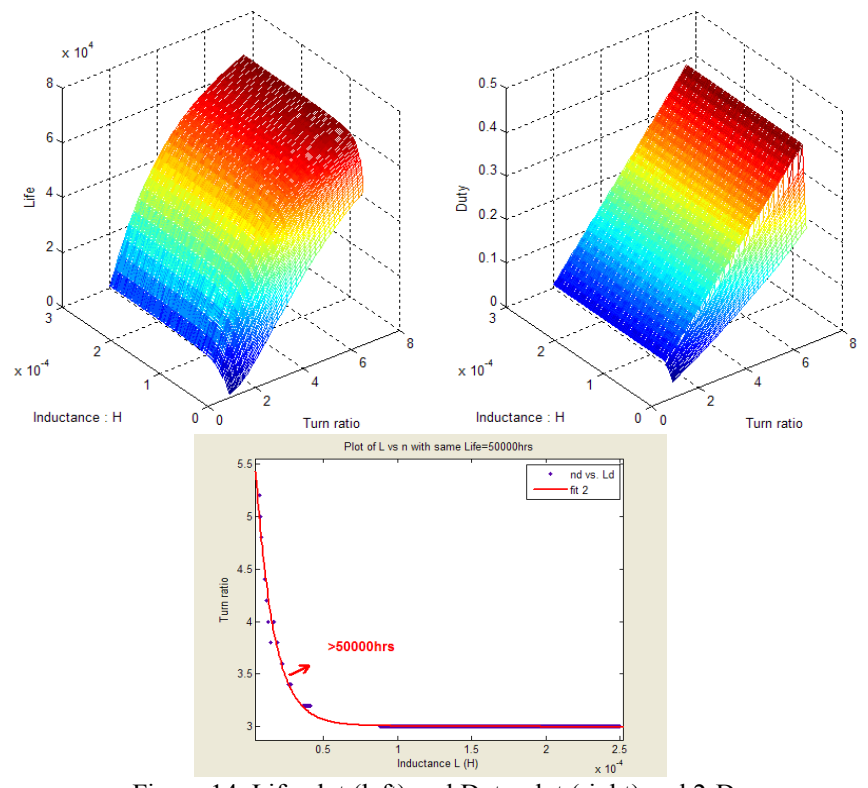

Figure 14. Life plot (left) and Duty plot (right) and 2-D life plot (bottom) for LED Driver 
power converter life. Analysis and comparison of the two

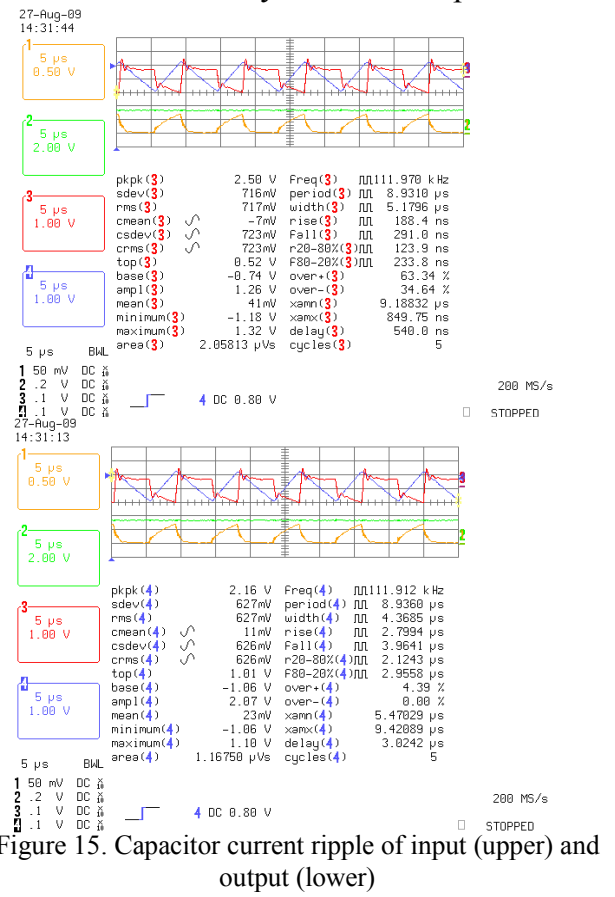

frequently used topologies (Flyback and Forward) in life aspect are made. Several parameters are optimized for long life design. They are the converter transformer turns ratio, the inductance and the duty cycle. A complete design example is also demonstrated to verify the method accuracy.

\section{REFERENCES}

[1] V. A. Sankaran, F. L. Rees and C. S. Avant, "Electrolytic capacitor life testing and prediction", Industry Applications Conference, 1997. Thirty-Second IAS Annual Meeting, IAS '97., Volume 2, 5-9 Oct.
1997, pp.1058-1065

[2] E. C. Aeloiza, J. H. Kim, P. Ruminot and P. N. Enjeti, "A Real Time Method to Estimate Electrolytic Capacitor Condition in PWM Adjustable Speed Drives and Uninterruptible Power Supplies", Power Electronics Specialists Conference, 2005. PESC '05. IEEE 36th, 16 June 2005, pp.2867-2872

[3] Hao Ma and Linguo Wang, "Fault diagnosis and failure prediction of aluminum electrolytic capacitors in power electronic converters", IEEE Industrial Electronics Society 31st Annual Conference, IECON 2005, 66 Nov. 2005, pp. 6 pp.-

[4] A. Riz, D. Fodor, O. Klug and Z. Karaffy, "Inner gas pressure measurement based life-span estimation of electrolytic capacitors", Power Electronics and Motion Control Conference, 2008. EPE-PEMC 2008. 13th, 1-3 Sept. 2008, pp. 2096-2101

[5] M. L. Gasperi, "Life prediction model for aluminum electrolytic capacitors", Industry Applications Conference, 1996. Thirty-First IAS Annual Meeting, IAS '96., Volume 3, 6-10 Oct 1996, pp.1347-1351

[6] M. L. Gasperi, "Life prediction modeling of bus capacitors in AC variable-frequency drives", IEEE Transactions on Industry Applications, Volume 41, Issue 6, Nov.-Dec. 2005, pp.1430-1435

[7] S. K. Maddula and J. C. Balda, "Lifetime of Electrolytic Capacitors in Regenerative Induction Motor Drives", Power Electronics Specialists Conference, 2005. PESC '05. IEEE 36th, 16-16 June 2005 pp.153-159

[8] Yaow-Ming Chen, Hsu-Chin Wu, Ming-Wei Chou and Kung-Yen Lee, "Online Failure Prediction of the Electrolytic Capacitor for LC Filter of Switching-Mode Power Converters", IEEE Transactions on Industrial Electronics, Volume 55, Issue 1, Jan. 2008, pp.400-406

[9] M. Huber, W. Amrhein, S. Silber, M. Reisinger, G. Knecht, G. Kastinger, "Ripple Current Reduction of DC Link Electrolytic Capacitors by Switching Pattern Optimisation", Power Electronics Specialists Conference, 2005. PESC '05. IEEE 36th, 16-16 June 2005, pp. $1875-1880$

[10] Maniktala, Sanjaya., "Switching power supply design \& optimization", McGraw-Hill Professional, 2005, pp. 5-7, 324, 361-369

[11] Rubycon Corporation, "Technical Notes for Electrolytic Capacitor" www.rubycon.com

[12] CDE Cornell Dubilier, "Application Guide Aluminum Electrolytic Capacitors" www.cornell-dubilier.com

[13] Reliability Prediction of Electronic Equipment, Military Handbook 217 F, 1995.

[14] Maniktala, Sanjaya., "Switching power supply design \& optimization", McGraw-Hill Professional 2005, pp5-7, 361-369 